\title{
Killer yeasts as biocontrol agents of spoilage yeasts and bacteria isolated from wine
}

\author{
Miguel Fernández de Ullivarri, Lucía M. Mendoza a , and Raúl R. Raya \\ CERELA-CONICET, Chacabuco 145, San Miguel de Tucumán (4000), Argentina
}

\begin{abstract}
During the winemaking process Saccharomyces cerevisiae is the main yeast species but other yeasts called non-Saccharomyces as well as different species of lactic acid bacteria (LAB) are also present. Then, one strategy to prevent or reduce microbial contamination during the winemaking process is the use of killer yeasts. The aim of this study was to evaluate the killer activity (KA) of autochthonous yeasts from Northwest region of Argentine (S. cerevisiae Cf8 and Wickerhamomyces anomalus Cf20) on spoilage yeasts and in LAB of the wine. The KA was evaluated using cell-free supernatants obtained from pure and mixed cultures of strains Cf8-Cf20. S. cerevisiae Cf8 showed a growth reduction between 7 and $48 \%$ on D. anomala BDa15, P. membranifaciens BPm481 and Z. bailii Bzb317 while W. anomalus Cf20 exhibited KA of 20, 61, 91 and 92\% against B. bruxellensis Ld1, D. anomala BDa15, P. membranifaciens BPm481 and P. guilliermondii Cd6, respectively. Killer mixed supernatants showed growth inhibition similar to strain Cf20. Screening against LAB showed that both killer toxins were able to inhibit the growth of L. hilgardii $5 \mathrm{w}$ as well as to reduce a $16-31 \%$ histamine production by this LAB strain. These results confirm the potential of autochthonous killer yeasts as biocontrol agents in winemaking process. The mixed culture $S$. cerevisiae Cf8-W. anomalus Cf20 presented a wide range of KA on spoilage yeasts as well as on L. hilgardii. Therefore, the use of killer yeasts as starter cultures would allow producing wines with controlled quality.
\end{abstract}

\section{Introduction}

During the winemaking process there is a predominance of the fermentative yeast Saccharomyces cerevisiae, which is used as starter culture of the alcoholic fermentation. However, during wine fermentation other yeasts called non-Saccharomyces as well as different species of lactic acid bacteria (LAB) are also present [1]. Yeasts of the genera Dekkera/Brettanomyces as well as Pichia guilliermondii and $P$. membranifaciens are generally considered wine contaminants during the fermentation stage or post-fermentation due to the production of phenolic aromas [2]. On the other hand, among wine LAB some species as Lactobacillus hilgardii and Pediococcus pentosaceus are also considered undesirable bacteria mainly for its ability to produce biogenic amines, compounds that affect the sanitary and sensory quality of wines [1]. One strategy to prevent or reduce microbial contamination during the winemaking process is the use of killer yeasts as starter cultures. These yeasts produce proteic toxins that inhibit the growth of unwanted yeasts and fungi, but its effect on wine LAB has not been reported yet $[1,3,4]$. The aim of this study was to evaluate the killer activity (KA) of autochthonous yeasts from Northwest region of Argentine, S. cerevisiae Cf8 and Wickerhamomyces anomalus $\mathrm{Cf} 20$ on different strains of spoilage yeasts and LAB of wine.

\footnotetext{
${ }^{a}$ Corresponding author: 1mendoza@cerela.org.ar
}

\section{Materials and methods}

\subsection{Strains and growth media}

Yeasts and bacteria used in this study are listed in Tables 1 and 2, respectively. The autochthonous killer strains $S$. cerevisiae Cf8 and $W$. anomalus Cf20 were isolated from wineries of Northwestern region of Argentina. Spoilage yeasts were gently provided to us from Yeast collection of San Juan University (Argentina). LAB strains were obtained from Microbiology Institute of Tucuman National University (Argentina).

Depending on the experiments, the yeasts were cultured in: YPD broth $(10 \mathrm{~g} / \mathrm{L}$ yeast extract, $20 \mathrm{~g} / \mathrm{L}$ peptone, $20 \mathrm{~g} / \mathrm{L}$ glucose) buffered at different $\mathrm{pH}$ with $0.1 \mathrm{M}$ citric acid/dibasic sodium phosphate; YPD-MB agar (YPD supplemented with $30 \mathrm{mg} / \mathrm{L}$ methylene blue, $20 \mathrm{~g} / \mathrm{L}$ agar). Depending on the experiments bacteria were cultured in MRS broth, MRS agar or basal medium supplemented with histidine 1\% (BM-Histidine) described by Joosten and Northolt [5]. Media were sterilized by filtering or autoclaving at $121^{\circ} \mathrm{C}$ for $20 \mathrm{~min}$. Microorganisms were incubated at $28^{\circ} \mathrm{C}$.

\subsection{Production of killer cell-free supernatants}

Killer strains $S$. cerevisiae Cf8 and W. anomalus Cf20 of were inoculated at $1 \times 107$ cells $/ \mathrm{mL}$ in pure and mixed cultures into YPD broth $\mathrm{pH} 4.0$ and incubated for $96 \mathrm{~h}$ at $20^{\circ} \mathrm{C}$. Yeast cells were separated from the supernatants by

This is an Open Access article distributed under the terms of the Creative Commons Attribution License 4.0, which permits unrestricted use, distribution, and reproduction in any medium, provided the original work is properly cited. 
Table 1. Killer and sensitive yeast strains used in this study.

\begin{tabular}{|c|c|c|c|}
\hline Species & Strain & $\mathbf{P}^{*}$ & Characteristics \\
\hline Saccharomyces cerevisiae & Cf8 & $\mathrm{K}+$ & Autochthonous $^{\mathrm{a}}$ \\
\hline Wickerhamomyces anomalus & Cf20 & $\mathrm{K}+$ & Authochthonous ${ }^{\mathrm{a}}$ \\
\hline Pichia guilliermondii & Cd6 & $\mathrm{K}-$ & Authochthonous/spoilage \\
\hline \multirow{2}{*}{ Zygosaccharomyces bailli } & BZb317 & $\mathrm{K}-$ & Spoilage $^{b}$ \\
\hline & $\mathrm{Ld} 2$ & $\mathrm{~K}-$ & Spoilage ${ }^{b}$ \\
\hline Dekkera anomala & BDa15 & $\mathrm{K}-$ & Spoilage ${ }^{b}$ \\
\hline Schizosaccharomyces pombe & BSp399 & $\mathrm{K}-$ & Spoilage ${ }^{b}$ \\
\hline Pichia membranifaciens & BPm 481 & $\mathrm{~K}-$ & Spoilage ${ }^{b}$ \\
\hline Dekkera bruxellensis & Ld1 & $\mathrm{K}-$ & Spoilage $^{b}$ \\
\hline
\end{tabular}

Table 2. Inhibitory effect of Cf8 and Cf20 killer supernatants on wine lactic acid bacteria.

\begin{tabular}{lllllll}
\hline L.hilgardii & Cf8 & Cf20 & P.pentosaceus & Cf8 & Cf20 \\
\cline { 2 - 3 } 5w & + & + & E2p & - & - \\
6F & - & - & $10 p$ & - & - \\
6D & - & - & Xp & - & - \\
X1B & - & - & E5 & - & - \\
N4L & + & + & $9 p$ & - & - \\
5A & - & - & $13 p$ & - & - \\
N7L & - & - & X2p & - & - \\
5S & - & - & $12 p$ & - & - \\
\hline
\end{tabular}

centrifugation at $10,000 \mathrm{~g}$ for $10 \mathrm{~min}$. Control supernatant was obtained treating $\mathrm{Cf} 20$ cell-free supernatant at $100{ }^{\circ} \mathrm{C}$ for $1 \mathrm{~h}$ to denature killer toxin.

\subsection{Inhibitory effect on wine spoilage yeasts}

Spoilage yeasts were inoculated at $1 \times 10^{6}$ cell $/ \mathrm{mL}$ in the killer- and control- cell-free supernatants. Cultures were incubated at $20^{\circ} \mathrm{C}$ for $48 \mathrm{~h}$ and absorbance at $600 \mathrm{~nm}$ $\left(\mathrm{A}_{600}\right)$ was measured. Killer activity $(\mathrm{KA})$ was expressed as \% reduction of absorbance according to the following formula:

$$
K A=100-A x / A C x 100 .
$$

Where $A_{x}$ is the absorbance of cultures in killer supernatants, and $A_{C}$ is the absorbance of cultures in control supernatants.

\subsection{Inhibitory screening assay on wine lactic acid bacteria (LAB)}

LAB strains (Table 2) were cultured as a lawn in MRS agar plates and $50 \mu \mathrm{L}$ of killer cell-free supernatants concentrated $10 \times$ by ultrafiltration ( $30 \mathrm{kDa}$, Amicon) were spotted on the agar. Control supernatants (heat treated) were also spotted on the agar. Plates were incubated at $20^{\circ} \mathrm{C}$ for 5-7 days. Inhibitory activity was considered positive when a clear zone with no growth was detected in the agar.

\subsection{Effect of killer supernatants on growth and histamine production of Lactobacillus hilgardii 5w}

Cultures of L. hilgardii 5w in MB-histidine supplemented with $10 \times$ killer- and control-cell-free supernantants (final $1 \times$ ) were carried out and incubated at $20^{\circ} \mathrm{C}$ for $48 \mathrm{~h}$. After incubation, cultures were centrifuged and filtrated to separate bacterial cells. Supernatants were deproteinized with trichloroacetic acid (TCA) $100 \% \mathrm{w} / \mathrm{v}$ and stored at $-20{ }^{\circ} \mathrm{C}$. Histamine concentration was quantified by RPHPLC (C18 Novapack column, 60 A, $4 \mu \mathrm{m}$ (Phenomenex, Torrance, USA) with previous derivatization with $\mathrm{O}$ phtaldialdehyde [6].

\section{Results and discussion}

\subsection{Inhibitory effect on wine spoilage yeasts}

$S$. cerevisiae Cf8 supernatant produced a growth reduction between 7 and $48 \%$ on D. anomala BDa15, $P$. membranifaciens $\mathrm{BPm} 481$ and $Z$. bailii Bzb317 (Fig. 1A) while $W$. anomalus Cf20 exhibited KA of 20, 61, 91 and $92 \%$ against B. bruxellensis Ld1, D. anomala BDa15, P. membranifaciens BPm481 and P. guilliermondii Cd6, respectively (Fig. 1B). Killer mixed supernatants showed growth inhibition similar to strain Cf20 (data not shown). These results demonstrate the biocontrol potential of these killer strains on spoilage yeasts, noting that $P$. guilliermondii $\mathrm{Cd} 6$ is an autochthonous strain from northwestern region of Argentina as Cf8 and Cf20 strains. These findings are in concordance with the literature, which express that killer toxins from $S$. cerevisiae have narrow inhibition spectra, while those belonging from $W$. anomalus often present broad inhibition spectra [8-10].

Bibliographic reports frequently make reference to the inhibitory effect of one killer strain or its toxin acting on sensitive or spoilage yeasts [11-13]. This is the first report about the effect of combined killer strains and its toxins in the inhibitory activity against spoilage yeasts as a strategy to increase the inhibitory capacity of a starter culture.

\subsection{Inhibitory effect on wine $L A B$}

As shown in Table 2, screening assay of concentrated killer cell-free supernatants $(>30 \mathrm{kDa})$ against $\mathrm{LAB}$ showed that $\mathrm{Cf8}$ and $\mathrm{Cf} 20$ supernatants were able to inhibit 

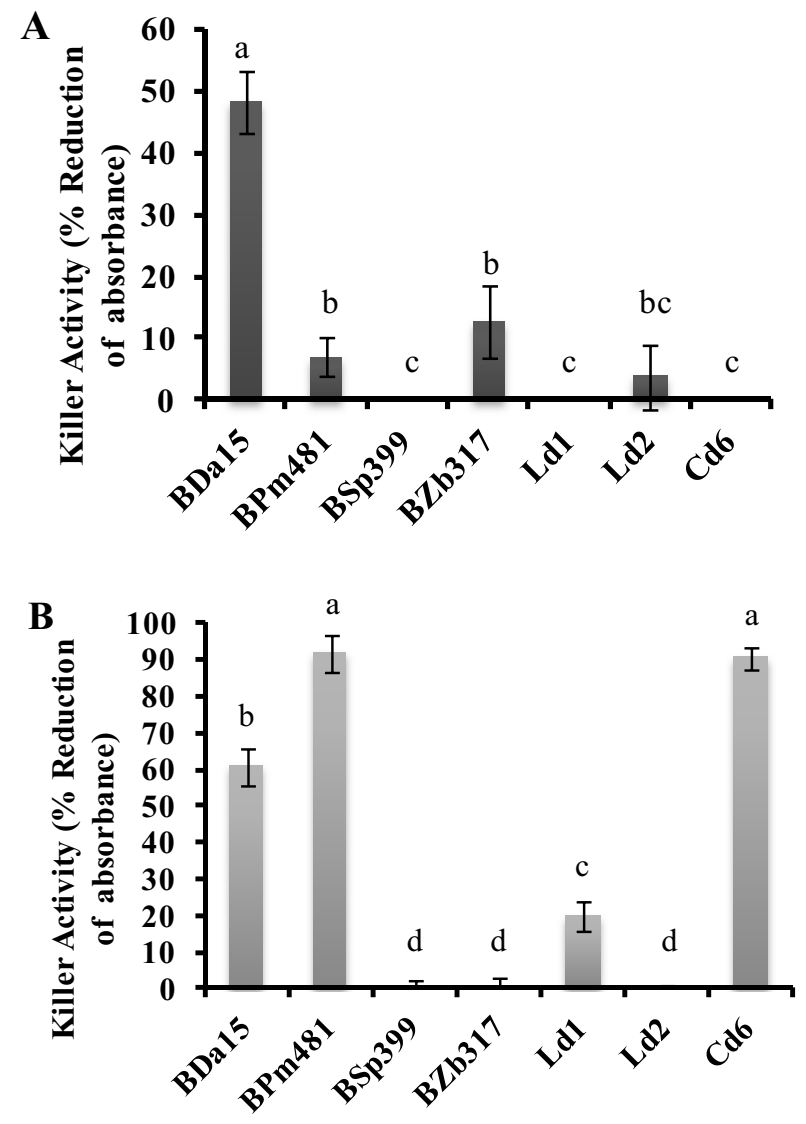

Figure 1. Killer activity of the cell-free supernatants from $S$. cerevisiae $\mathrm{Cf} 8$ (A) and. W. anomalus $\mathrm{Cf} 20$ (B) against the wine spoilage yeast strains $D$. anomala $\mathrm{BDa} 15, P$. membranifaciens BPm481, Sch. pombe BSp399, Z. bailli BZb317, B. bruxellensis $\mathrm{Ld} 1$, Z. bailli $\mathrm{Ld} 2$ and P. guilliermondii Cd6.

the growth of L. hilgardii $\mathrm{N} 4 \mathrm{~L}$ and $5 \mathrm{w}$, the latter a histamine-producing strain. When the inhibitory effect of Cf8 and Cf20 supernatants was evaluated on L. hilgardii $5 \mathrm{w}$ in liquid cultures, it was observed a longer lag phase and lower final growth (Fig. 2A) as well as a 16-31\% decrease in biogenic amine production, being higher the inhibitory effect in the coculture supernatant (Fig. 2B). Several authors have reported the inhibitory effect of non-Saccharomyces killer yeast supernatants on different bacterial groups, mainly gram positive bacteria [14-16]. No studies about the mechanism of action of the killer toxins on prokaryotic cells have been performed. Although the toxic mechanisms remain unknown, the decrease on histamine production may be due to the growth inhibition of L. hilgardii. This is the first report of the effect of killer yeasts on wine-relevant $\mathrm{LAB}$ and the first report of the inhibitory effect of a $S$. cerevisiae killer strain on bacteria.

The literature has extensively reported studies about the use of simultaneous and sequential starter cultures of Saccharomyces and non-Saccharomyces strains in order to improve the wine flavor and avoid the excessive production of aroma compounds $[8,17,18]$. In contrast, this work propose the use a combination of a $S$. cerevisiae killer strain with remarkable enological properties as Cf8 [7] and a potent non-Saccharomyces killer strain to optimize
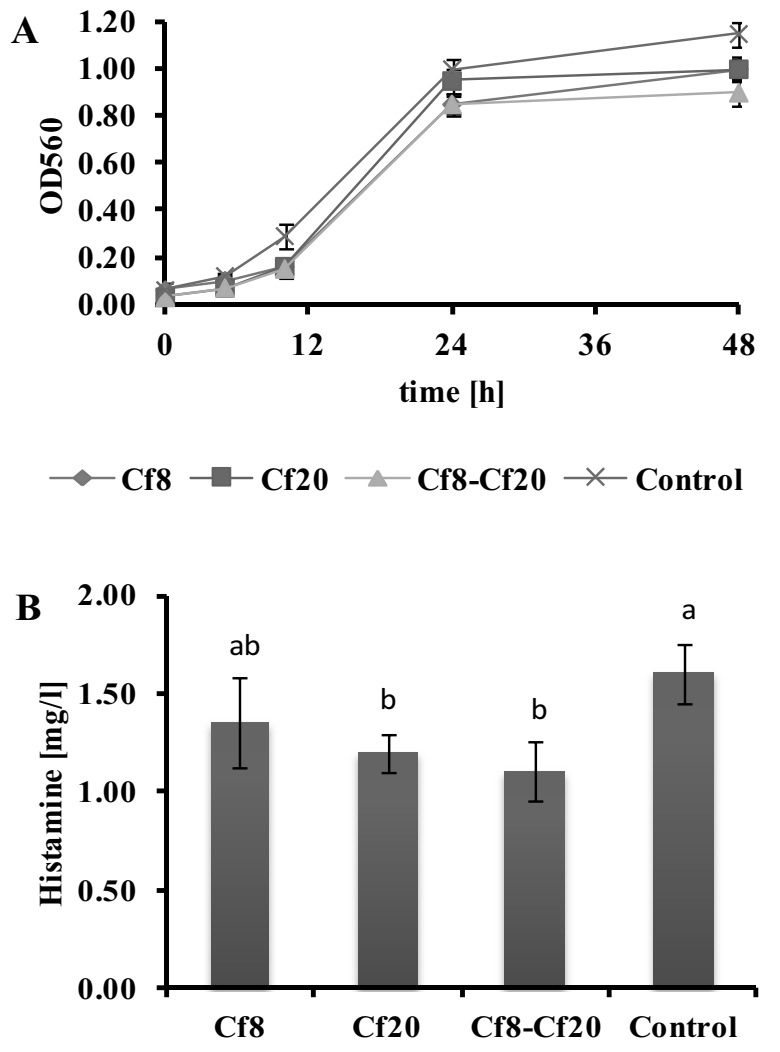

Figure 2. Effect of killer supernatants of pure and mixed cultures of $S$. cerevisiae Cf8 and W. anomalus $\mathrm{Cf} 20$ on growth (A) and histamine production (B) of L. hilgardii $5 \mathrm{w}$.

their inhibitory activity against wine relevant spoilage microorganisms during the fermentation.

The results of this work confirm the potential of autochthonous killer yeasts as biocontrol agents in winemaking process. The mixed culture $S$. cerevisiae Cf8W. anomalus Cf20 presented a wide range of KA on spoilage yeasts as well as on L. hilgardii. Therefore, the use of killer yeasts as starter cultures would permit to produce wines with controlled quality.

\section{References}

[1] K. C. Fugelsang, C. G. Edwards, Wine microbiology (Chapman \& Hall, New York, 1997)

[2] V. Loureiro, M. Malfeito-Ferreira, Spoilage yeasts in the wine industry. Int. J. Food. Microbiol. 86(1), 2350 (2003)

[3] F. İzgü, D. Altınbay, T. Acun, Killer toxin of Pichia anomala NCYC 432; purification, characterization and its exo- $\beta$-1, 3-glucanase activity. Enzyme Microb. Tech. 39(4), 669-676 (2006)

[4] G. Bleve, F. Grieco, G. Cozzi, A. Logrieco, A. Visconti, Isolation of epiphytic yeasts with potential for biocontrol of Aspergillus carbonarius and A. niger on grape. Int. J. Food. Microbiol. 108(2), 204-209 (2006)

[5] H. M. L. J. Joosten, M.D. Northolt, M. D., Detection, growth, and amine-producing capacity of lactobacilli 
in cheese. Appl. Environ. Microb., 55(9), 2356-2359 (1989)

[6] S. Fadda, G. Vignolo, G. Oliver, Tyramine degradation and tyramine/histamine production by lactic acid bacteria and Kocuria strains. Biotechnol. Lett. 23(24), 2015-2019 (2001)

[7] M. Fernández de Ullivarri, L. M. Mendoza, R. R. Raya, M. E. Farías, M. E., Killer phenotype of indigenous yeasts isolated from Argentinean wine cellars and their potential starter cultures for winemaking. Biotechnol. Lett.,33(11), 2177-2183 (2011)

[8] M. Ciani, F. Fatichenti, Killer Toxin of Kluyveromyces phaffii DBVPG 6076 as a Biopreservative agent to control apiculate wine yeasts. Appl. Environ. Microb. 67(7), 3058-3063 (2001)

[9] W. Magliani, S. Conti, M. Gerloni, D. Bertolotti, L. Polonelli, L., Yeast killer systems. Clin. Microbiol. Rev., 10(3), 369-400 (1997)

[10] V. Passoth, M. Olstorpe, J. Schnürer, Past, present and future research directions with Pichia anomala. Anton. Leeuw. Int. J. G. 99(1), 121-125 (2011)

[11] S. Muccilli, S. Wemhoff, C. Restuccia, F. Meinhardt, Exoglucanase-encoding genes from three Wickerhamomyces anomalus killer strains isolated from olive brine. Yeast, 30(1), 33-43 (2013)

[12] A. Santos, M. San Mauro, E. Bravo, D. Marquina, PMKT2, a new killer toxin from Pichia membranifaciens, and its promising biotechnological properties for control of the spoilage yeast Brettanomyces bruxellensis. Microbiology, 155(2), 624-634 (2009)

[13] A. Santos, E. Navascués, E. Bravo, D. Marquina, Ustilago maydis killer toxin as a new tool for the biocontrol of the wine spoilage yeast Brettanomyces bruxellensis. Int. J. Food. Microbiol. 145(1), 147-154 (2011)

[14] M. C. Meneghin, V. R. Reis, S. R. Ceccato-Antonini, Inhibition of bacteria contaminating alcoholic fermentations by killer yeasts. Braz. Arch. Biol. Techn. 53(5), 1043-1050 (2010)

[15] F. Izgü, D. Altinbay, Killer toxins of certain yeast strains have potential growth inhibitory activity on gram-positive pathogenic bacteria. Microbios. 89(358), 15-22 (1996)

[16] G. Morace, S. Manzara, G. Dettori, F. Fanti, S. Conti, L. Campani, C. Chezzi, Biotyping of bacterial isolates using the yeast killer system. Eur. J. Epidemiol. 5(3), 303-310 (1989)

[17] M. Bely, P. Stoeckle, I. Masneuf-Pomarède, D. Dubourdieu, Impact of mixed Torulaspora delbrueckii-Saccharomyces cerevisiae culture on high-sugar fermentation. Int. J. Food Microbiol. 122(3), 312-320 (2008)

[18] L. M. Mendoza, M. G. Merín, V. I. Morata, M. E. Farías. Characterization of wines produced by mixed culture of autochthonous yeasts and Oenococcus oeni from the northwest region of Argentina. J. Ind. Microbiol. Biot. 38(11), 1777-1785 (2011) 